\title{
Ferramentas diagnósticas de Lentivirose de Pequenos Ruminantes: padronização da técnica de ELISA indireto
}

\section{Diagnostic tools of small ruminant lentiviruses: standardization of indirect ELISA}

\author{
Caliandra Bona Nascimento ${ }^{*}$, Raymundo Rizaldo Pinheiro², Francisco Selmo Fernandes Alves ${ }^{2}$, \\ Roberta Lomonte Lemos de Brito², Apoliana de Sousa Rodrigues², Ricardo Abílio Bezerra e Silva', \\ Ney Rômulo de Oliveira Paula', Maria do Carmo de Souza Batista'
}

RESUMO: As Lentiviroses de Pequenos Ruminantes (LVPR) incluem a Maedi-Visna (MV) em ovinos e a Artrite Encefalite Caprina (CAE). Essas enfermidades estão difundidas no mundo e são responsáveis por grandes perdas na produtividade destes animais. Os LVPR são vírus RNA da subfamília Lentivirinae que causam uma infecção persistente, sendo a detecção precoce uma das formas mais eficientes para limitar sua disseminação no rebanho. Visando contribuir com essas questôes, este experimento foi realizado na Universidade Federal do Piauí (UFPI) em parceria com a Embrapa Caprinos e Ovinos, com o objetivo de padronizar a técnica de ensaio imunoenzimático indireto e compará-lo com a imunodifusão em gel de agarose no diagnóstico da CAE. Foram utilizadas 696 amostras de soros de caprinos machos e fêmeas oriundas do banco de soros da Unidade de Pesquisa de LVPR do Centro de Ciências Agrárias da UFPI. As amostras foram coletadas no período de janeiro de 2007 a março de 2010. Na padronizaçáo, verificou-se que $0,25 \mu \mathrm{g}$ de proteína/poço, diluiçáo de 1:200 do soro e concentraçáo de 1:3.000 do conjugado anticorpo anti-IgG cabra apresentaram os melhores resultados. O ponto de corte obtido foi de 0,36 . Na comparação, o Imunodifusão em Gel de Ágar (IDGA) detectou $128(18,4 \%)$ amostras positivas, e o ELISA indireto (ELISA-i), 259 (37,2\%). A sensibilidade e a especificidade do teste ELISA-i com relação ao IDGA foi de $94,5 \%$ e $75,7 \%$, respectivamente. Verificou-se maior índice de positividade em caprinos acima de seis meses ( $\mathrm{p}<0,05)$, e nos machos obteve-se prevalência de 56,7\% em comparação às fêmeas, 35,4\%, (p<0,01).

PALAVRAS-CHAVE: diagnóstico; lentiviroses de pequenos euminantes; ELISA-i; IDGA.

\begin{abstract}
The Small Ruminant Lentiviruses (SRLVs) include Maedi-Visna (MV) of sheep and Caprine ArthritisEncephalitis (CAE). These diseases are widespread and responsible for major production losses regarding sheep and goats. The SRLV is a RNA virus of the subfamily Lentivirus genus that causes persistent infections in goats. Early detection is one of the best ways to limit its spread in the herd. To contribute to these issues, this experiment was conducted at Universidade Federal do Piauí in partnership with Embrapa Goats and Sheep, with the objective of standardizing the technique of indirect ELISA (i-ELISA) and to compare it with Immunodiffusion in Agarose Gel to diagnose Caprine Lentiviruses (LC). Six hundred ninety six serum samples were used from the University Veterinary Hospital, Universidade Federal do Piaui, from January 2007 to March 2010. Standardization showed that $0.25 \mu \mathrm{g}$ protein/well, a 1:200 dilution of the serum and concentration of 1:3,000 of the conjugated anti-goat IgG presented the best results. It was observed that the Agar Gel Immunodiffusion (AGID) detected 128 (18.4\%) positive samples, and ELISA, 259 (37.2\%). The sensitivity and specificity of i-ELISA regarding AGID were $94.5 \%$ and $75.7 \%$, respectively. A higher prevalence was observed among animals older than six months $(\mathrm{p}<0.05)$. The prevalence among males was of $56.7 \%$, and among females, $35.4 \%(\mathrm{p}<0.01)$.
\end{abstract}

KEYWORDS: diagnosis; small ruminant lentiviruses; i-ELISA; AGID. 


\section{INTRODUÇÃO}

No Brasil, a partir de 1978 , foram realizadas inúmeras importaçốes de caprinos de raças leiteiras exóticas oriundas de vários países (Lima, 2002). Grande parte dos animais adquiridos não possuía padróes sanitários adequados, o que propiciou a introdução de agentes infecciosos, dentre eles os agentes da Artrite Encefalite Caprina (CAE) e da Maedi-Visna (MV). Estes formam o grupo das Lentiviroses de Pequenos Ruminantes (LVPR), doenças caracterizadas por cronicidade, progressividade, lentidáo e indução de baixa imunogenicidade (ADAms et al., 1983).

O aparecimento tardio dos sinais clínicos dessas enfermidades e as práticas coletivas de manejo leiteiro contribuíram para a sua dispersão por todo o país. Os animais acometidos permanecem por longos períodos nos rebanhos sem manifestarem sintomas. A demora no diagnóstico dessas enfermidades geralmente induz ao comprometimento do desempenho produtivo, além de acarretar perdas econômicas significativas para os produtores (Pinheiro et al., 2005; Batista et al., 2004). Por conta disso, os estudos sobre a sanidade desses pequenos ruminantes devem ser considerados prioritários para o sucesso de programas de controle e/ou erradicação dessas enfermidades, principalmente aqueles que visem à descoberta de técnicas de diagnóstico, diretas ou indiretas, eficientes e capazes de indicar a presença ou a ausência dos LVPR nos rebanhos (ANDRIoli et al., 2010)

A Organização Mundial de Epizootias (OIE) preconiza a utilização da Imunodifusão em Gel de Ágar (IDGA) e do Ensaio Imunoenzimático (ELISA) no diagnóstico de LVPR (OiE, 2006).

A IDGA é um teste que apresenta boa aceitação devido ao seu baixo custo, especificidade e praticidade de execução. O ELISA requer um antígeno mais puro do que o utilizado na IDGA, assim como uma estrutura laboratorial mais sofisticada; entretanto, nos programas de erradicação, o monitoramento da infecção é geralmente baseado na sorologia por meio de ELISAs comerciais ou padronizados, que são mais sensíveis que o IDGA (Brinkhof; Van MaAnen, 2007), fáceis de serem executados e passíveis de automaçáo, o que possibilita examinar um grande número de amostras, além de apresentarem estabilidade dos reagentes e o emprego destes em quantidades mínimas (OIE, 2006).

Considerando que as LVPR constituem sério problema sanitário, que ocasionam prejuízos às exploraçôes de ovinos e caprinos em todo o mundo, e que a descoberta de testes seguros e economicamente viáveis para diagnosticá-las é muito importante para evitar ou minimizar a sua disseminação, este trabalho foi realizado com o objetivo de padronizar o teste ELISA indireto (ELISA-i) para o diagnóstico sorológico da CAE e realizar o estudo comparativo da sensibilidade e especificidade entre ELISA-i e IDGA.

\section{MATERIAL E MÉTODOS}

\section{Amostras}

Para a realização dos testes sorológicos de ELISA-i e IDGA, utilizou-se material oriundo do banco de soro da Unidade de Pesquisa em LVPR, integrante do Laboratório de Ciências Fisiológicas do Departamento de Morfofisiologia Veterinária do Centro de Ciências Agrárias da Universidade Federal do Piauí, o qual foi composto por 696 amostras enviadas por médicos veterinários ao Hospital Veterinário Universitário. O objetivo foi diagnosticar as LVPR nas amostras coletadas no período de 2007 a 2010 nos estados do Maranhão e Piauí. Os soros eram provenientes de caprinos que não apresentavam um padrão racial específico, abrangendo tanto animais de alto padrão racial como aqueles animais de tipos raciais diversos, com a idade variando de 3 meses até acima de 36 meses, de ambos os sexos.

\section{Detecção sorológica de anticorpos para Artrite Encefalite Caprina}

\section{Imunodifusão em Gel de Ágar}

O teste sorológico de IDGA foi realizado com kit nacional de uso comercial (Biovetech, Recife - PE), seguindo as orientações do fabricante. Esse teste utiliza um antígeno específico do CAEV, a proteína do capsídeo (p28). A primeira leitura foi feita 24 horas após a incubação, e depois de 48 horas realizou-se a leitura definitiva, verificando-se a presença ou a ausência das linhas de precipitação (continuidade ou não de linhas entre o soro reagente e soro teste), de acordo com a técnica preconizada por CuTLIP et al. (1992).

\section{ELISA-i}

- Antígenos: $\mathrm{O}$ antígeno utilizado para este teste foi produzido na Embrapa Caprinos e Ovinos, sendo obtido do cultivo de células de membrana sinovial caprina infectadas com a cepa CAEV Cork, com o título inicial de $10^{5} \mathrm{TCID}_{50} / \mathrm{mL}$ e purificado por ultracentrifugação e colchão de sacarose, segundo a metodologia descrita por PinHeIro et al. (2006). Foram testadas quatro concentraçôes diferentes de proteína do antígeno viral: 1,0; 0,5; 0,25 e 0,125 $\mu$ g. Para determinar a concentração ótima do antígeno viral, foi escolhida a mais baixa concentraçáo, a qual demonstrou a positividade da reação para qualquer diluiçấo do soro padrão positivo, e que não foi significativamente menor do que a produzida pela concentração imediatamente superior.

- Soro e conjugado: Foram testadas quatro diluiçôes de conjugado "IgG jumento anticabra": 1:2.000; 1:3.000; 1:4.000 e 1:10.000. Os soros foram testados em três diluiçôes (1:50; 1:100; 1:200). Concomitantemente, avaliou-se a ausência de 
reatividade do soro padráo negativo para as mesmas diluições do padrão positivo. Foram utilizados os soros padrão positivo e negativo do kit Americano (Veterinary Diagnostic Technology, Inc.), segundo metodologia de PinHeIRo (2001).

\section{Padronização do ELISA}

Durante toda a padronização do ELISA-i, seguiram-se as determinaçóes da Organização Mundial da Saúde Animal (OIE) com o intuito de realizar o controle de qualidade e a replicabilidade do teste. Os soros foram testados em duplicata, sendo que os resultados foram expressos em densidade ótica (DO).

$\mathrm{O}$ teste foi conduzido em microplacas de polivinil de alta capacidade de adsorção, flexíveis com 96 poços (Costar). A sensibilização foi realizada com $100 \mu \mathrm{L}$, contendo $0,25 \mu \mathrm{L}$ de antígeno, em tampáo carbonato-bicarbonato $(0,05 \mathrm{M}$, $\mathrm{pH} 9,6$ ) por 1 hora a $37^{\circ} \mathrm{C}$ em estufa. Em seguida, foi armazenado durante a noite, sob refrigeração. Passado este período, os poços foram lavados duas vezes com uma soluçáo de lavagem ( $\mathrm{NaCl}$ e Tween 20). Os sítios livres de ligação de proteínas que porventura estivessem presentes foram bloqueados pela adição do tampão de bloqueio (PBS, $2 \%$ de caseína) e incubação sob agitação a $37^{\circ} \mathrm{C}$ em estufa, por uma hora, seguida de dupla lavagem.

Depois, foram adicionados $100 \mu \mathrm{L}$ dos soros controle positivos e negativos (em quadruplicata) do kit americano (Veterinary Diagnostic Technology, Inc.) aos poços pré-determinados e, na sequência, dos soros testes (em duplicata), todos diluídos em 1:200 em tampáo de incubação (PBS + Tween+ Caseína), que permaneceram por uma hora na estufa a $37^{\circ} \mathrm{C}$. Logo depois foram realizadas seis lavagens, e $100 \mu \mathrm{L}$ do conjugado anticorpo anti-IgG caprina foram distribuídos, marcados com peroxidase (Sigma), na diluição (1:3.000) em solução tampão de incubação. Incubou-se por uma hora, a $37^{\circ} \mathrm{C}$ em estufa.

Foram lavados novamente por seis vezes, e as reaçóes foram reveladas pela adição de $100 \mu \mathrm{L}$ do substrato, uma solução de $0,2 \mathrm{mg} / \mathrm{mL}$ de fenilenodiamina (OPD) em presença de tampão citrato $(10 \mathrm{~mL}, 1 \mathrm{M}, \mathrm{pH} 5,0)$ e $2 \mu \mathrm{L}$ de $\mathrm{H}_{2} \mathrm{O}_{2}(0,02 \%)$ por 15 minutos, em câmara escura, à temperatura ambiente. A reaçáo foi inibida por adição de $20 \mu \mathrm{L}$ de $\mathrm{H}_{2} \mathrm{SO}_{4}$ (1:20). A intensidade da cor da reaçáo foi determinada por absorvância em leitor de microplacas de ELISA no comprimento de onda $490 \mathrm{~nm}$.

\section{Validação do ELISA-i}

A validaçáo do ELISA-i foi realizada por meio de um estudo comparativo entre os resultados obtidos no ELISA-i e os resultados do kit IDGA. Os valores relativos à sensibilidade e à especificidade da técnica ELISA em relação à IDGA foram calculados segundo SMith (1991). A comparação entre os dois testes foi realizada através do teste do qui-quadrado com correçáo de Yates $\left(\chi^{2}\right)$ (Tyler; Cullor, 1989).

\section{Estatística}

Com base nos resultados sorológicos, foram calculadas a especificidade e a sensibilidade dos testes realizados. Calculou-se também a frequência da infecçáo pelo CAEV nos diferentes estratos para analisar a existência de diferenças significativas entre os resultados obtidos para os atributos sexo e faixa etária. Foram utilizados somente 365 animais dos 696, sendo 60 machos e 305 fêmeas, uma vez que o teste do qui-quadrado $\left(\chi^{2}\right)$ foi utilizado para a comparação das médias com o auxílio do programa EPI-INFO (DeAN et al., 1992).

\section{RESULTADOS E DISCUSSÃO}

Os resultados de sensibilidade e especificidade do ELISA-i deste estudo, quando comparados ao IDGA, evidenciaram valores distantes dos encontrados por CASTRO et al. (1999), que destacaram menor sensibilidade $(54,2 \%)$ e maior especificidade (100\%).

Deve-se levar em consideração que além dos fatores inerentes aos testes, existem animais com resposta imunológica seletiva para determinados antígenos (Johnson et al., 1983; Rimstad et al., 1994). Além disso, conforme discutido por Pinheiro et al. (2010), em um rebanho controlado para LVPR utilizando sempre o mesmo antígeno, pode haver o efeito de seleção entre os animais. Quando se aplica um teste com antígeno diferente daquele utilizado no programa de controle, é possível encontrar um maior número de animais positivos, além do fato de que pequenas alteraçóes antigênicas podem influenciar a sensibilidade do teste de IDGA (ReIschaK, 2000) bem como o processamento do ELISA, no qual as lavagens com PBS contendo Tween 20 podem ocasionar a exposição de certos epítopos.

O ponto de corte foi determinado pela fórmula citada por FreY et al. (1998), utilizando 41 soros de animais não reagentes, negativos por IDGA e Proteína C-Reativa (PCR), oriundos do banco de soros da Embrapa Caprinos e Ovinos, sendo: $0,21+3 \mathrm{x}(0,05)$, cujo resultado foi 0,36 .

Neste estudo verificou-se que o IDGA detectou $128(18,4 \%)$ amostras positivas, e o ELISA evidenciou 259 (37,2\%), conforme demonstrado na Tabela 1 , sendo que todas as amostras fracas positivas no teste de IDGA foram positivas no ELISA-i, que detectou $18,8 \%$ a mais de animais reagentes que o IDGA.

Em estudos comparando estes dois testes, DANTAS et al. (2008), Pinheiro (2001), Castro (1998), Celer Jr. et al. (1998) e SimARD; Briscoe (1990) relataram que o ELISA apresentou percentuais de 22,9, 44,5, 25,4, 15,5 e 15,5, respectivamente, a mais que a IDGA na detecção de animais positivos.

Utilizando o ELISA com sistema de amplificação do sinal enzimático pela avidina-biotina, CASTRO (1998) detectou $84 \%$ de animais positivos a mais que a IDGA; porém, houve aumento do custo e do tempo do teste. 
Ao padronizar uma técnica sorológica para um determinado agente, deve-se considerar e avaliar a sensibilidade e a especificidade, as quais envolvem a comparação entre resultados desses testes e o estado real de infecçáo do animal (LARA et al., 2002). A sensibilidade do teste ELISA-i em relação à IDGA obtido no presente estudo foi de 94,5\% (Tabela 2). Esses dados corroboram os relatados por DE ANDRÉs et al. (2005) que utilizaram um ELISA-i para detecção do CAEV e encontraram uma sensibilidade de 97,3\%. Concordam também com os relatos de Heckert et al. (1992) e Cruz et al. (2009), que obtiveram 98,3\% e 93,93\%, respectivamente, de sensibilidade para o ELISA-i.

Segundo Torres et al. (2009), o teste ELISA é uma técnica de mais sensibilidade em relação à IDGA, considerando-se o mecanismo de interação antígeno-anticorpo que ambos envolvem. Enquanto testes imunoenzimáticos requerem a interação de apenas um epítopo por anticorpo para obter um resultado positivo, a precipitação em gel de ágar requer múltiplas interaçóes antígeno-anticorpo por reação. Por conta disso, há indicação de que as amostras negativas na IDGA sejam testadas novamente pelo ELISA. Neste teste, a especificidade do ELISA-i em relação à IDGA foi de 75,7\% (Tabela 2), sendo inferior ao de Dantas et al. (2008), de 82\%.

O diagnóstico sorológico de animais infetados pelos agentes das LVPR é difícil, considerando que alguns animais podem apresentar baixos títulos de anticorpos, soroconversão tardia ou, ainda, soroconversão intermitente de soropositividade e soronegatividade, exigindo-se assim provas mais sensíveis (Torres et al., 2009).

O ELISA-i foi padronizado no sentido de obter a máxima diferença entre as DO de soros negativos e positivos.
Verificou-se que 0,25 $\mu \mathrm{g}$ de proteína/poço, a diluição dos soros de 1:200 e a concentração de 1:3.000 do conjugado IgG jumento anticabra apresentaram os melhores resultados. O protocolo obtido apresentou um bom rendimento, com a necessidade de menores quantidades de antígeno $(0,25 \mu \mathrm{g}$ de proteína/poço) do que as empregadas por Dantas et al. (2008), que utilizaram $2 \mu \mathrm{g}$ de proteína/poço, e Pinheiro (2001), que utilizou $0,5 \mu \mathrm{g}$ de proteína/poço.

O índice kappa obtido (50\%) aproxima-se do encontrado por LARA et al. (2002) (77\%), indicando que há uma boa concordância entre os testes; porém, foi superior aos achados de Dantas et al. (2008), que obtiveram índice kappa de 32\%, demonstrando baixa concordância entre os testes.

A análise da prevalência por sexo demonstrou, assim como descrito por Pinheiro (2001), que os machos são mais afetados pela enfermidade $(56,7 \%)$ do que as fêmeas (Tabela 3$)$. Esse dado se contrapóe aos achados de Crawford; Adams (1981), Melo; Franke (1997) e Saraiva Neto (1993), os quais não verificaram diferença $(\mathrm{p}>0,05)$ quanto ao sexo. Batista et al. (2004), estudando animais no Piauí, observaram que $77,78 \%$ dos animais reagentes eram fêmeas, e $22,22 \%$ eram machos. Sabe-se que as diferenças no manejo de machos e fêmeas, o descarte prematuro das últimas, o período de permanência na baia e a extensão do contato entre os animais podem pode explicar diferenças de soroprevalência entre os sexos (BERriatua et al., 2003). Entretanto, segundo CRAwFord; AdAMs (1981), não existem fatores relacionados ao sexo que predisponham à infecção pelos LVPR.

Rowe; EAST (1997) observaram maior taxa de soroconversão em fêmeas negativas cruzadas com machos positivos do que que em fêmeas negativas cruzadas com machos negativos.

Tabela 1. Comparação dos resultados obtidos em amostras de soros pelas técnicas Imunodifusão em Gel de Ágar e ELISA-i.

\begin{tabular}{lcccccc} 
& Reagente & $\%$ & Não reagente & $\%$ & Total \\
\hline IDGA & 128 & 18,4 & 568 & 81,6 & 696 \\
\hline ELISA-i & 259 & 37,2 & 437 & 62,8 & 696 \\
\hline
\end{tabular}

Índice kappa = 50\%; IDGA: Imunodifusão em Gel de Ágar; ELISA-i: Ensaio Imunoenzimático indireto.

Tabela 2. Valores de sensibilidade e especificidade do teste ELISA em relação à Imunodifusão em Gel de Ágar.

\begin{tabular}{lcc} 
Valores & ELISA/IDGA & $\%$ \\
\hline Sensibilidade & $121 / 128$ & $94,5 \%$ \\
\hline Especificidade & $430 / 568$ & $75,7 \%$ \\
\hline
\end{tabular}

IDGA: Imunodifusão em Gel de Ágar; ELISA: Ensaio Imunoenzimático.

Tabela 3. Resultados do ELISA-i em amostras de sangue de caprinos machos e fêmeas.

\begin{tabular}{lcccc} 
& Reagente & $\%$ & Não reagente & $\%$ \\
Macho & $34^{\mathrm{a}}$ & 56.7 & $26^{\mathrm{a}}$ & 43.3 \\
\hline Fêmea & $108^{\mathrm{b}}$ & 35.4 & $197^{\mathrm{b}}$ & 64.6 \\
\hline
\end{tabular}

a: letras diferentes na mesma coluna indicam diferença significativa $\left(\chi^{2} ; p<0,01\right)$ entre os sexos; ELISA-i: Ensaio Imunoenzimático indireto. 
Tabela 4. Resultados do ELISA-i em amostras de sangue de caprinos de acordo com a idade.

\begin{tabular}{llc} 
Idade & Reagente & Total de amostras \\
\hline$<6$ meses & $23(25,8 \%)^{\mathrm{b}}$ & 89 \\
\hline $6-18$ meses & $64(41,6 \%)^{\mathrm{a}}$ & 154 \\
\hline $18-36$ meses & $28(50,9 \%)^{\mathrm{a}}$ & 55 \\
\hline$>36$ meses & $27(40,3 \%)^{\mathrm{a}}$ & 67 \\
\hline
\end{tabular}

a: letras diferentes na mesma coluna indicam diferença significativa $\left(\chi^{2} ; p<0,05\right)$ entre as idades; ELISA-i: Ensaio Imunoenzimático indireto.

PinHeiro et al. (1999) relataram que a presença de reprodutores positivos no rebanho tem grande influência na disseminação da CAE, haja vista o potencial de transmissão do vírus pelo sêmen (ANDrioli et al., 2006). A maior incidência entre reprodutores, principalmente naqueles com valor genético e econômico elevado, é preocupante, pois estes são mantidos conjuntamente com muitas fêmeas durante a estação reprodutiva, ou são usados em técnicas de reprodução assistida. Mesmo com o uso de biotecnologias e lavagens não há a eliminação total do lentivírus caprino no sêmen (ANDrioli et al., 2006), ou seja, um único macho infectado pode ser responsável pela contaminação de um grande número de animais no rebanho. Este dado foi confirmado por Souza et al. (2009), que comprovaram a transmissão do CAEV pelo sêmen contaminado experimentalmente ao constatarem que um único ejaculado de um reprodutor infectado pode disseminar o vírus em até $100 \%$ das fêmeas inseminadas artificialmente.

Quanto à idade dos animais positivos, verificou-se maior prevalência $(\mathrm{p}<5 \%)$ nos caprinos mais velhos quando comparados aos jovens (Tabela 4). Os caprinos de 18 a 36 meses de idade representaram $50,9 \%$ de soropositividade, seguidos de animais de 6 a 18 meses $(41,6 \%)$. Saraiva Neto (1993) relatou que animais mais velhos possuem, geralmente, mais elevado padráo zootécnico e, portanto, são mantidos por mais tempo no rebanho do que os demais.

Os dados relativos à faixa etária encontrados neste trabalho estão de acordo com os de Batista et al. (2004), Pinheiro (2001), Fernandes (1997), Saraiva Neto (1993) e Cutlip et al. (1992), os quais verificaram, em animais do Piauí, Ceará, São Paulo, Pernambuco e Estados Unidos, respectivamente, que a taxa de prevalência de animais reagentes aumenta com a idade. Também são concordantes com os achados de Dawson (1989), que encontrou maior percentual de soropositividade para LVPR em caprinos com mais de cinco anos, e os de AL-QUDAH (2006), que relatou a existência de maior percentual de caprinos positivos dentre aqueles com mais de três anos de idade. Isso tende a ser explicado pela evolução lenta da enfermidade, o que proporciona maior probabilidade de exposição dos animais mais velhos ao vírus (McGuire, 1987).
Por outro lado, estudos realizados por Melo; Franke (1997) na regiāo metropolitana de Fortaleza indicaram maior positividade em animais mais jovens, atribuída à provável transmissão através do leite e/ou colostro. Em rebanhos com alta taxa de infecção é possível que os animais passem por soroconversão e se tornem infectados durante o primeiro ano de vida (EAst et al.,1987; LeginagoiKOA et al., 2006).

Os resultados deste experimento reforçam os estudos prévios realizados por BATISTA et al. (2004), que evidenciaram a presença de pequenos ruminantes positivos para LVPR em rebanhos do estado do Piauí. Isso deve servir de alerta para as autoridades sanitárias em relação à necessidade de serem instituídas medidas de controle do tráfego de animais e à exigência de certificação negativa em feiras e eventos agropecuários, a fim de que seja minimizada a disseminação dessas enfermidades.

\section{CONCLUSÕES}

O ELISA-i é um teste mais sensível do que a IDGA para a detecção de animais soropositivos para LVPR. O ELISA-i apresenta alta sensibilidade e boa especificidade, podendo ser utilizado como teste de diagnóstico para as LVPR.

O ELISA-i e a IDGA demonstraram concordância nos resultados, sendo que ambos podem ser recomendados e utilizados como métodos de diagnóstico individual e em levantamentos epidemiológicos para determinação de prevalências das LVPR em rebanhos.

Os caprinos machos e os adultos são os mais acometidos pela infecção por LVPR. Os estados do Piauí e do Maranhão possuem rebanhos infectados com os agentes das LVPR.

\section{AGRADECIMENTOS}

À EMBRAPA-CNPC e à Universidade Federal do Piauí, pelo uso da estrutura e do suporte técnico. Ao CNPq e ao MAPA pelo apoio financeiro durante todo o experimento. 


\section{REFERÊNCIAS}

ADAMS, D.S.; KLEYJER-ANDERSON, P.; CARLSON, J.L.; MCGUIRE. T.C.; GORHAM, J.R. Transmission and control of Caprine ArthritisEncephalitis Virus. American Journal of Veterinary Research, Illinois, v.44, p.1670-1675, 1983.

AL-QUDAH, K.; AL-MAJALI, A.M.; ISMAIL, Z.B. Epidemiological studies on caprine arthitis-encephalitis virus infection in Jordan. Small Ruminant Research, v.66, p.181-186, 2006.

ANDRIOLI, A.; GOUVEIA, A.M.G.; MARTINS, A.S.; SANTOS, D.O. PINHEIRO, R.R. Fatores de risco na transmissão do lentivírus caprino pelo sêmen. Pesquisa Agropecuária Brasileira, v.4 1, n.8, p.1313-1319, 2006

ANDRIOLI, A.; GOUVEIA, A.M.G.; ARAGÃO, M.A.C.; MARTINEZ, P.M.M. Avaliação de antígenos para o diagnóstico de lentivírus em rebanho caprino sob programa de controle. Arquivos do Instituto Biológico, v.77, p.133-137, 2010.

BATISTA, M.C.S.; CASTRO, R.S.; CARVALHO, F.A.A; CRUZ, M.S.P.; SILVA, S.M.M.S.; REGO, E.W.; LOPES, J.B. Anticorpos antilentivirus de pequenos ruminantes em caprinos integrantes de nove municípios piauienses. Ciência Veterinária nos Trópicos, v.7, p.75-81, 2004.

BERRIATUA, E.; ALVAREZ, V.; EXTRAMIANA, B.; GONZALEZ, L.; DALTABUIT, M.; JUSTE, R. Transmission and control implications of seroconversion to maedi-visna vírus in Basque dairy-sheep flocks. Preventive Veterinary Medicine, v.60, p.265-279, 2003.

BRINKHOF, J.; VAN MAANEN, C. Evaluation of five enzyme-linked immunosorbent assays and an agar gel immunodiffusion test for detection of antibodies to small ruminant lentiviruses. Clininical and Vaccine Immunology, v.4, p.1210-1214, 2007.

CASTRO, R.S. Lentivírus de pequenos ruminantes: ensaios imunoenzimáticos, perfil sorológico e inferências filogenéticas. 1998. 132 f. Tese (Doutorado) - Universidade Federal de Minas Gerais, Belo Horizonte, 1998.

CASTRO, R.S.; LEITE, R.C.; RESENDE, M.; GOUVEIA, A.M.G. A Labelled avidin-biotin ELISA to detect antibodies to Caprine Arthritis-encephalitis virus in goat sera. Veterinary Research Communications, v.23, p.515-522, 1999.

CELER JR.V; NEMCOVA, H.; ZANONI, R.G.; PETERHANS, E. Serologic diagnosis of ovine lentiviruses by whole virus ELISA and AGID test. Journal of Veterinary Medicine, v.45, p.183-188, 1998.

CRUZ, R.B.; PUTINI, V.N.; SANTANA, G.S.; JORGE, J.S.; COELHO, I.; SILVA, D.L.; ZACHARIAS, F.; TIGRE, D.; CERQUEIRA, R.B. Estudo comparativo da sensibilidade e da especificidade de Elisa indireto com o teste de imunodifusão em gel de agarose no diagnóstico sorológico da artrite encefalite caprina (CAEV) Revista Acadêmica Ciências Agrárias e Ambientais, v.7, p.355-364, 2009.

CUTLIP, R.C.; LEHMKUHL, H.D.; SACKS, J.M. Prevalence of antibody to caprine arthritis-encephalitis virus in goats in the United States. Journal of the American Veterinary Medical Association, v.200, p.802-805, 1992
DANTAS, T.V.M; ARAUUJO, S.A.C.; PINHEIRO, R.R.; SILVA, J.B.A; RICARTE, A.R.F.; RIBEIRO, A.L.; TEIXEIRA, M.F.S. Desenvolvimento e padronização de um ELISA indireto para diagnóstico de MaediVisna em ovinos. Ciência Animal Brasileira, v.9, p. 181-187, 2008.

DAWSON, M. The caprine arthritis-encephalitis syndrome. Veterinary Annual, v.29, p.98-102, 1989.

DE ANDRES, D.; KLEIN, D.; WATT, N.J.; BERRIATUA, E.; TORSTEINSDOTTIR, S.; BLACKLAWS B.A.; HARKISS, G.D. Diagnostic tests for small ruminant lentiviruses. Veterinary Microbiology, v.107, p.49-62, 2005.

DEAN, A.G.; DEAN, J.A.; BURTON, A.H.; DICKER, R.C. Epi-info, version 6: a word processing, database and statistic program for epidemiology on microcomputers. Atlanta, Georgia, Center for Disease Control. 1992. 302p.

EAST, N.E.; ROWE, J.D; MADEWELL, B.R.; FLOYD, K. Serologic prevalence of caprine arthritis-encephalitis virus in California goat dairies. Journal of the American Veterinary Medical Association, v.190, p.182-186, 1987

FERNANDES, M.A. Artrite encefalite caprina. Contribuição para o estudo epidemiológico em rebanhos leiteiros criados no Estado de São Paulo. 1997. 83 f. Dissertação (Mestrado) - Universidade de São Paulo, São Paulo, 1997.

FREY, A.; DI CANZIO, J.; ZURAKOWSI, D.A. A statistically defined endpoint titer determination method for immunossays. Journal of Immunological Methods, v.22 1, p.35-41, 1998.

HECKERT, R.A.; MCNAB, W.B.; RICHARDSON, S.M.; BRISCOE, M.R. Evaluation of an enzyme-linked immunosorbent assay for the detection of antibodies to caprine arthritis-encephalitis virus in goat serum. Canadian Journal of Veterinary Research, v.56, p.237-241, 1992

JOHNSON, G.C.; BARBET, A.F.; KLEVJERANDERSON, P.; MCGUIRE, T.C. Preferential immune response to virion surface glycoproteins by caprine arthritis-encephalitis virus-infected goats. Infectivity Immunology, v.2, p.657-665, 1983.

LARA, M.C.C.S.H.; BIRGEL JUNIOR, E.H.; REISCHAK, D.; MOOJEN, V.; GREGORY, L.; OLIVEIRA, J.C.F.; BRGEL, E.H. Identificação imuno-sorológica de anticorpos anti-vírus da artrite-encefalite dos caprinos: comparação das técnicas de imunodifusão em gel de ágar, ensaio imunoenzimático e imunofluorescência indireta. Arquivos do Instituto Biológico, v.69, p. 1-5, 2002.

LEGINAGOIKOA, I; JUSTE, R.A.; BARADIKA, J.; AMORENA, B.; DE ANDRES, D,; LUJAN, L.; BADIOLA, J.; BERRIATUA, E. Extensive rearing hinders maedi-visna virus (MVV) infection in sheep. Veterinary Research, v.37, p.767-778, 2006.

LIMA,P.P. Virus da artrite encefalite caprina: isolamento e caracterização parcial do gene gag. 2002. 57 f..Dissertação (Mestrado) - Universidade Federal de Minas Gerais, Belo Horizonte, 2002. 
MCGUIRE, T.C. The immune response to viral antigens as a determinant of arthritis in caprine arthritis-encephalitis virus infection. Veterinary Immunology and Immunopathology, v.17, p.465-470, 1987.

MELO, A.C.M.; FRANKE, C.R. Soroprevalência da infecção pelo vírus da Artrite-Encefalite Caprina (CAEV) no rebanho de caprinos leiteiros da região da grande Fortaleza, Ceará, Brasil. Ciência Rural, v.27, p.113-117, 1997.

Organização mundial da saúde animal. Oie. Manual de testes diagnósticos e vacinas para animais terrestre, 2006. Disponível em: <http://www.oie.int>. Acesso em: dez. 2010.

PINHEIRO, R.R. Vírus da Artrite-Encefalite Caprina: Desenvolvimento e padronização de ensaios imunoenzimáticos (ELISA e Dot-blot) e estudo epidemiológico no Estado do Ceará. 2001. 115 f. Tese (Doutorado) Universidade Federal de Minas Gerais, Belo Horizonte, 2011.

PINHEIRO, R.R.; GOUVEIA, A.M.G.; ANDRIOLI, A. Prevalência da Artrite Encefalite Caprina em reprodutores caprinos nas principais regiões leiteiras do Estado do Ceará. Revista Brasileira de Reprodução Animal, v.23, p.421-423, 1999.

PINHEIRO, R.R.; GOUVEIA, A.M.G.; ALVES, F.S.F. Prevalência da infecção pelo vírus da artrite-encefalite caprina no estado do Ceará, Brasil. Ciência Rural, v.31, p.449-454, 2003.

PINHEIRO, R.R.; GOUVEIA, A.M.G.; ALVES, F.S.F;; ANDRIOLI, A. Medidas carpo-metacarpianas como índice articular clínico em caprinos. Revista Brasileira de Medicina Veterinária, v.27, p.170-173, 2005.

PINHEIRO, R.R.; OLORTEGUI, C.C.; GOUVEIA, A.M.G.S.; ARAUJO, S.C.; ANDRIOLI, A. Desenvolvimento de dot-blot para detecção de anticorpos para o vírus da Artrite Encefalite Caprina. Revista Portuguesa de Ciências Veterinárias, v.101, p.51-56, 2006.

PINHEIRO, R. R.; GOUVEIA, A. M. G.; ANDRIOLI, A. M. C.; ARAGÃO, P. M.; MARTINEZ. Avaliação de antígenos para o diagnóstico de lentivírus em rebanho caprino sob programa de controle. Arq. Inst. Biol., v.77, p.133-137, 2010
REISCHAK, D. Lentivírus de pequenos ruminantes: Imunofluorescência utilizando isolados brasileiros para diagnóstico sorológico de infecção em ovinos e caprinos. 2000. 132 f. Dissertação (Mestrado) Universidade Federal do Rio Grande do Sul, Porto Alegre, 2000.

RIMSTAD, E.; EAST, N.; DEROCK, E.; HIGGINS, J.; PEDERSEN, N. Detection of antibodies to caprine arthritis encephalitis virus using recombinant gag proteins. Archive Virology, v. 134, p.345356, 1994.

ROWE, J.D.; EAST, N.E. Risk factors for transmission and methods for control of caprine arthritis-encephalitis virus infection. The Veterinary Clinics of North America. Food Animal Practice, v.13, p.33-53, 1997.

SARAIVA NETO, A.O. Soroprevalência da Artrite Encefalite Caprina em plantéis caprinos leiteiros no Estado de Pernambuco. 1993. 70 f. Dissertação (Mestrado) -Universidade Federal Rural de Pernambuco, Recife, 1993.

SIMARD, C.L.; BRISCOE, M.R. An enzyme-linked immunosorbent assay for detection of antibodies to maedi-visna virus in sheep. II. Comparison to conventional agar gel immunodifusion test. Canadian Journal of Veterinary Research, v.54, p.451-456, 1990.

SOUZA, K.C.; RODRIGUES, A.S. ; PINHEIRO, R.R.; BRITO, R.L.L.; DIAS, R.P.; BRITO, I.F.; SANTOS, D.O.; ANDRIOLI, A. Influência da carga viral na transmissão sexual do vírus da artrite-encefalite caprina. In: IV SINCORTE, 2009, João Pessoa. Anais. João Pessoa: EMEPA, 2009. v. CD.

TYLER, J.W.; CULLOR, J.S. Titers, tests, and truisms: rational interpretation of diagnostic serologic testing. Journal of the American Veterinary Medical Association, v.194, p. 1550-1558, 1989.

TORRE, J.A.; CAMPOS, G.S.; FREITAS, M.M.; BRANDÃO, C.F.L.; SARDI, S.I. Produção de antígeno viral para o sorodiagnóstico da artrite-encefalite caprina utilizando um teste imunoenzimático. Revista de Ciências Médicas e Biológicas, v.2, p.107-114, 2009. 